\title{
Support, Opposition, Emotion and Contentious Issue Risk Perception
}

Bourassa, M. , Doraty, K. , Berdahl, L. , Fried, J. and Bell, S.

Author post-print (accepted) deposited in CURVE February 2016

Original citation \& hyperlink:

Bourassa, M. , Doraty, K. , Berdahl, L. , Fried, J. and Bell, S. (2016) Support, Opposition, Emotion and Contentious Issue Risk Perception. International Journal of Public Sector Management, volume 29 (2): 201-216

http://dx.doi.org/10.1108/IJPSM-10-2015-0172

ISSN 0951-3558

DOI 10.1108/IJPSM-10-2015-0172

Copyright $(\subseteq$ and Moral Rights are retained by the author(s) and/ or other copyright owners. A copy can be downloaded for personal non-commercial research or study, without prior permission or charge. This item cannot be reproduced or quoted extensively from without first obtaining permission in writing from the copyright holder(s). The content must not be changed in any way or sold commercially in any format or medium without the formal permission of the copyright holders.

This document is the author's post-print version, incorporating any revisions agreed during the peer-review process. Some differences between the published version and this version may remain and you are advised to consult the published version if you wish to cite from it. 


\title{
SUPPORT, OPPOSITION, EMOTION AND CONTENTIOUS ISSUE RISK PERCEPTION
}

\begin{abstract}
Purpose

Research on emotion in the context of risk perception has historically focused on negative emotions, and has emphasized the effect of these negative emotions on the perception of risk amongst those who oppose (rather than support) contentious issues. Drawing on theory, we hypothesize that both positive and negative emotions are correlated with risk perceptions regarding contentious public issues and that this occurs amongst supporters and opponents alike.

\section{Design/methodology/approach}

Our paper explores the relationship between emotions and perceived risk through consideration of the highly contentious case of nuclear energy in Saskatchewan, Canada. The analysis uses data from a representative telephone survey of 1,355 residents.
\end{abstract}

\section{Findings}

The results suggest that positive emotions, like negative emotions, are related to nuclear energy risk perceptions. Emotions are related to risk perception amongst both supporters and opponents.

\section{Research limitations/implications}

The dataset's limited number of emotion measures and single public issue focus, combined with the survey's cross-sectional design, make this research exploratory in nature. Future research should incorporate multiple positive emotions, explore opposition and support across a range of contentious public issues, and consider experimental models to assess causal relationships. 


\section{Practical implications}

The paper offers insights into how public sector managers must be cognizant of the emotional underpinnings of risk perceptions amongst both supporters and opponents of contentious public issues.

\section{Originality/value}

This paper builds on and expands previous work by considering both positive and negative emotions and both supporters and opponents of contentious issues.

\section{Key Words}

Emotion, risk perception, risk management, nuclear energy, contentious issues, public attitudes.

\section{Article Classification}

Research paper 


\section{Introduction}

Many public sector choices involve consideration of activities that involve risk, such as environmental damage or negative health effects. Risk perception is a subjective assessment of the likelihood and severity of an event with negative consequences occurring (Sjöberg et al., 2004). Contentious issues within the public sector frequently involve managing risk perceptions (Hood and Smith, 2013; Halachmi, 2005), which can be a main cause of opposition to contentious activities (Sjöberg et al., 2004). In addition, as contentious issues often require public participation (King et al., 1998), an improved understanding of risk perceptions may facilitate effective public participation.

Common narratives often paint opponents of risky activities as being driven by emotions and supporters as being driven by cognition (Fischer, 1995). Such portrayals are similarly found in the risk perception research; early research on emotions in the context of risk analysis investigated the strong connection between negative emotions such as dread and the perception of risk (Fischoff et al., 1978; Slovic, 1987), suggesting an underlying assumption that emotions are the preoccupation of opponents (rather than supporters) of risky propositions. While risk research continues to support the idea that emotions are related to risk perception (e.g. Loewenstein et al., 2001), such investigations have focused primarily on negative emotions and are perhaps simplistic in portraying emotions as irrational gut reactions (Fahlquist and Roeser, 2015). Researchers are only recently considering the range of nuanced emotions that might impact on individual assessments of risk (Dohle et al., 2012; Keller et al., 2012).

This distinction between opponents as emotional and supporters as rational in their assessments of risk is intriguing, because there is other research which shows humans combine both cognition and emotion in all kinds of evaluations and decision making. Specifically, 
traditional theories of attitude formation (Eagly and Chaiken, 2007), appraisal theory (Lazarus, 1991), and theories of persuasion (Petty and Cacioppo, 1986) suggest that, in general, humans regardless of their attitude towards something - integrate both cognition and emotion in their evaluations.

Our paper investigates the extent to which emotion - negative and positive - matters to opponents and supporters in the context of risk perceptions and nuclear power generation. Nuclear energy is a relevant context for this study because it conjures a span of emotional responses that affect risk perception (Peters et al., 2004; Sjöberg, 2003); further, it is an example of a contentious public sector management issue where the public's perceptions of risk frequently differs, and is more negative, from that of technical experts (Sjöberg, 1999a).

Our study takes place in Saskatchewan, Canada, globally the second largest uranium producer with over $20 \%$ of the world's mined uranium. The province does not generate nuclear energy and has only a small, $20 \mathrm{KW}$ research reactor. In 2008, a proposal to build a reactor in Saskatchewan generated considerable public discussion (World Nuclear Association, 2013); the reactor was never built. Subsequently, three communities in the province considered hosting a repository for Canada's nuclear fuel waste. Together, these events make nuclear energy decisionmaking highly salient amongst the Saskatchewan public.

Using original survey data, we consider how three emotions - anger, fear, and excitement - relate to individual perception of health risks, environmental risks, and the overall risk-benefit balance of nuclear power. We also considers if the relationship between emotion and risk perception varies between supporters and opponents. Specifically, our study seeks to explore two research questions about nuclear energy risk perception: 
(1) What is the role of positive emotion, as compared to negative emotion, in individual perceptions of risk?

\section{(2) Do emotions matter to both opponents and supporters?}

By addressing these research questions, our study contributes to an improved understanding of how cognitive and emotional factors relate to risk perceptions. In addition, this research responds to calls for more behavioural analyses of political and economic systems (e.g., Jones, 2003). For public sector management research broadly, by exploring assumptions surrounding supporters and opponents of risky concerns, this research contributes to improved understanding of authentic public participation (King et al., 1998).

\section{Background}

\section{Emotion and Risk Perception}

Existing research points to a clear relationship between emotion, described as feelings or feeling states (Izard 2010), and risk perception (Loewenstein et al., 2001). The feelings as information hypothesis proposes that emotion influences risk perception in a cognitive way (Schwarz, 2011; Schwarz and Clore, 1996), with individuals treating emotions as information when rationally assessing risks. The risk as feelings hypothesis suggests that emotions serve as heuristics (mental shortcuts) that allow individuals to assess risk in a non-cognitive but efficient manner (Finucane et al., 2000; Loewenstein et al., 2001).

The relationship between emotion and risk perception is supported in other empirical analysis (Finucane et al., 2000). Researchers have demonstrated that emotions matter to risk perception in several scientifically/technologically complex policy fields, such as nanotechnology (Cobb and Macoubrie, 2004; Lee et al., 2005) and biotechnology (Savadori et al., 2004). Specific to nuclear risk perception, Sjöberg (2007) found that negative emotions were 
linked with people perceiving risks to be higher than benefits, while positive emotions were - to a lesser extent - linked with people perceiving that benefits outweigh risks. Feelings of worry and pessimism have been shown to positively correlate with risk perception of other nuclearrelated concepts, including not only nuclear power but also natural background radiation, domestic nuclear waste, nuclear waste transportation, and nuclear waste (Peters et al., 2004; Sjöberg, 1998a).

In our study, we build on previous research in this area and ask, what is the role of positive as compared to negative emotions on individual risk perceptions? Specifically, we investigate the connection between emotion towards nuclear energy and the perceived risk of nuclear energy. We hypothesize that three emotions - anger, fear, and excitement - are robust correlates of risk perception, even after controlling for knowledge, trust, and worldviews. Anger and fear are frequently studied negative emotions within the risk literature (e.g., Lerner and Keltner, 2001) and are intuitively important in the context of contentious issues. Excitement is a forward looking emotion, which is appropriate in this study. It is also an intense positive emotion and therefore a conservative test of the hypothesis; individuals are less likely to claim excitement than other, less intense positive emotions. Drawing on previous research, we hypothesize that those who report negative emotions (anger and fear) towards nuclear energy will be more likely to perceive nuclear energy as risky and respondents who report positive emotions (excitement) around nuclear energy will be less likely to perceive nuclear energy as risky. We anticipate that this relationship holds true for both opponents and supporters of nuclear energy, which we elaborate on in the next section. 


\section{Considering Differences Between Opponents and Supporters}

In the field of public policy, Fischer $(1995 ; 2003)$ has analyzed public participation in controversial issues and activities. He describes how certain opposing members of the public are seen as irrational and emotional (e.g., driven by frustration, rage, anxiety), and how industry and government experts - typically, those in support of a contentious action - attempt to counter this emotional irrationality through public awareness that promotes scientific knowledge and fact.

Similarly, from early stages of research on emotion and risk perception and on emotion and contentious issues generally, there appears to have been an underlying assumption that opponents are irrational (Fahlquist and Roeser, 2015; Fischoff et al., 1978; Slovic, 1987). In a variety of contexts where controversial issues are the focus, opponents have often been characterized as "emotional” and supporters as "rational” (Sjöberg, 2006). For example, research on the tensions around hunting concluded that "the activists are emotional, sentimental individuals, "bleeding hearts" who do not care or cannot understand a logical, scientific practice like hunting" (Einwohner, 1999, 66). Elsewhere, the animal rights movement is portrayed as overly emotional (Gaarder, 2011). Specific to nuclear policy, evidence similarly suggests opponents' perceptions of risk and emotions are tightly intertwined (e.g., Slovic et al., 1991).

In contrast, drawing on attitude, appraisal, and persuasion theories, we assume that emotions matter to evaluations of risk for both opponents and supporters of contentious issues like nuclear power. Across these theoretical accounts, evaluation and decision-making include both cognitive and affective (emotional) factors. Specifically, attitude theory suggests that attitudes (evaluations) have both cognitive and emotional components (Eagly and Chaiken, 2007). Appraisal theory also acknowledges that both emotions and cognitions matter to our appraisals of events (Lazarus, 1991). Finally, persuasion researchers suggest that both cognitive 
and affective (emotional) factors have a role in information processing more generally (Petty and Cacioppo, 1986).

In this study, we test the notion that emotions matter at both ends of the debate. Specifically, our second research question is: do emotions matter to both opponents and supporters of nuclear power? Drawing on theoretical reasoning, we anticipate that emotions will be instrumental in determining not only negative risk perception amongst opponents, but also positive risk perception amongst supporters. We expect that opponents are not only emotional and supporters are not only rational in calculating assessments of risk, but that in both cases, attitudes towards nuclear power are affectively-laden, and that this combines with rational assessments in their relationship with subjective risk. In testing these relationships, we control for several other factors linked to risk perceptions, described below.

\section{Other Factors in Risk Perception}

Aside from emotion, other determinants of risk perception include knowledge, trust, and worldviews. Previous literature has shown that greater scientific knowledge and factual awareness correlate with positive attitudes towards nuclear activities and hazards (European Commission, 2010; Greenberg and Truelove, 2010; McBeth and Oakes, 1996) and perceived benefits (Maharik and Fischhoff, 1993; Sjöberg and Drottz-Sjöberg, 1991).

When one lacks sufficient knowledge to make judgments (Siegrist and Cvetkovich, 2000), and/or to eliminate uncertainty and simplify risk assessments (Siegrist et al., 2005), trust in social actors might be used to inform risk perceptions. Specifically, a person may rely on social cues disseminated from groups perceived to be reliable (Siegrist and Cvetkovich, 2000). Prior studies have shown greater trust in industry and government (Bord and O'Connor, 1992; Pijawka and Mushkatel, 1992; Sjöberg, 1999b) and in managers and regulators of nuclear 
hazards (Biel and Dahlstrand, 1995; Flynn et al., 1992; Hallman and Wandersman, 1995) is linked to lower perception of risk and/or favourable attitudes towards nuclear applications.

In addition to knowledge and trust, worldviews are also related to risk

perceptions. Worldviews refer to social, cultural, and political attitudes that influence individuals' judgments (Slovic, 1999); different worldviews (including egalitarianism, hierarchy, and individualism) help individuals understand the world and make judgments perceived to be morally acceptable (Dake, 1991; Peters and Slovic, 1996). Research finds that egalitarians hold stronger negative opinions or show more opposition towards nuclear activities than individualists or hierarchists (Dake, 1991; Marris et al., 1998; Peters and Slovic, 1996; Sjöberg, 1998b).

In this study, we control for the impact of knowledge, trust, and worldviews on the relationship between emotions and risk assessment amongst both opponents and supporters.

\section{Summary}

This paper seeks to build on existing literature by examining both positive and negative emotions, and by considering how emotion influences risk perception across both opponents and supporters. Drawing on existing research and theory, we test the following hypotheses: (1) that respondents who report positive emotion (excitement) about nuclear energy will be less likely to perceive nuclear energy as risky; (2) that those who report negative emotions (anger and fear) about nuclear energy will be more likely to perceive nuclear energy as risky; and (3) that emotions are significant correlates within risk perception models for both opponents and supporters. Again, we control for knowledge, trust, and worldviews.

\section{Method}

This telephone survey was conducted in 2013 to better understand public attitudes towards the nuclear sector in Saskatchewan, Canada. Survey data were collected using a 
computer-assisted telephone interviewing (CATI) system and random digit dialing. When a resident answered a call, the interviewer asked to speak to the person in their household who is 18 years of age or older and is having the next upcoming birthday to ensure a more random representation of participants. A telephone number was contacted up to six times before removed from the sample. In total, 1,355 participants completed the telephone survey. The generalized response rate was $21 \%$ and the results of the survey are generalizable to the provincial population (18 years of age and above) with a margin of error $+/-2.66 \%, 19$ times out of 20 (95\% confidence interval).

As often occurs with telephone survey research, the sample overrepresented females and those 55 and older, while males and those aged 18-34 were underrepresented. During analysis, the data were weighted to reflect the population parameters according to 2011 Statistics Canada Census data for gender, age, and region.

-- insert Table 1 about here--

A full list of measures is in Table 1. The dependent variable of interest is nuclear power risk perception. The first dependent measure is not strictly a risk perception measure, but rather one that asked respondents to make an assessment of the balance of risks and benefits, an approach consistent with previous literature (Bak, 2001; Besley and Oh, 2014; Brossard and Nisbet, 2007; Cobb and Macoubrie, 2004). The second and third dependent measures asked respondents to assess the environmental and health risks of nuclear power.

The independent variables of interest are emotions. The survey included three measures that solicited emotional responses towards nuclear power generation (question order was randomized). The anger and fear measures are consistent with the operationalization of negative emotions in previous studies (Cobb and Macoubrie, 2004; Sjöberg, 2003, 2007). The positive 
measure of excitement is unique in this field of study. One possible limitation of these measures is the absence of a neutral category; some respondents may have chosen an emotional response when indifferent.

Key control variables included knowledge, worldviews, and trust. Four objective knowledge questions were combined into a single count measure, consistent with Bak (2001, 785); a single item was used to measure subjective knowledge. The worldviews questions were used in or adapted from previous studies (Dake, 1991; Hirsch and Baxter, 2011; Marris et al., 1998; Oltedal et al., 2004; Peters and Slovic, 1996; Slovic, 1999). The trust measure was a single-item evaluation of the extent to which a number of nuclear sector actors can be trusted. Finally, consistent with other studies, several socio-demographic variables were considered.

We used logistic regression analysis to explore the extent to which emotions increase the explanatory power of risk perception models, after other variables are controlled. For each analysis, the socio-demographic, worldviews, trust, and knowledge variables were entered into a first block ("Model A") and the emotions variables were entered into a second block ("Model B”). This highlights incremental explained variance of emotions, as well as which variables, if any, were rendered insignificant once emotions were added to the model. The results are in Table 2; for each independent variable, a negative logistic regression coefficient (B) and an odds ratio $(\operatorname{Exp}(B))$ below 1 signifies a negative relationship and can be interpreted as a decreased likelihood of perceiving nuclear power as risky. A positive relationship, indicated by a positive regression coefficient and an odds ratio above 1, suggests an increased likelihood of perceiving nuclear power as risky. --insert Table 2 about here-- 


\section{Findings}

We begin our analysis by considering the risk-benefit perception dependent variable (risks greater than benefits) (see Table 2). In the first model (Model A), we assess the relationship between risk-benefit perception and all variables except the emotions variables. This model has modest explanatory power $\left(\right.$ pseudo- $\left.\mathrm{R}^{2}=.288\right)$, and suggests a number of positive and negative correlates of risk-benefit perception. Specifically, we find that an individual's likelihood of perceiving the risks of nuclear energy to outweigh the benefits increases as egalitarianism increases and as trust in environmental groups increases. We also find a number of negative relationships: an individual's likelihood of stating that risks outweigh benefits decreases as trust in scientists and as age increases. In the second model (Model B), we introduce the three emotions variables in addition to the sociodemographic, worldviews, trust, and knowledge variables. In doing so, we find the model's explanatory power increases (pseudo- $\mathrm{R}^{2}$ $=.397$ ), and two of the three emotions variables are significant correlates with risk-benefit perception: an individual's likelihood of perceiving greater risks than benefits increases with anger, while it decreases with excitement. We also note that egalitarianism and age remain statistically significant correlates of risk perception after we add emotions to the model, whereas the trust measures do not.

Our analysis of environmental risk perception suggests a similar pattern. Again, our model that excludes the emotions variables (Model A) has moderate explanatory power (pseudo$\mathrm{R}^{2}=.371$ ). We find that an individual's likelihood of stating nuclear energy is environmentally dirty increases as egalitarianism, trust in environmental groups and (unexpectedly) trust in elected officials increase; conversely, a respondent's likelihood of perceiving nuclear energy to be environmentally dirty decreases as hierarchism, trust in regulators, trust in industry, age, 
income, and objective knowledge increase. When we add emotions to the model (Model B), the model's explanatory power increases (pseudo- $\mathrm{R}^{2}=.473$ ), and we find that two of the three emotions correlate to nuclear environmental risk perception: an individual's likelihood of stating that nuclear energy is environmentally dirty increases as fright increases, and decreases as excitement increases. In this model, the worldviews, as well as trust in regulators and industry, cease to be statistically significant correlates.

Finally, we again observe the relationship between emotions and risk perception with respect to our third dependent variable, health risk perception. In the model that excludes the emotions variables (Model A), we find that a respondent's likelihood of perceiving nuclear energy to be hazardous to human health increases as egalitarianism, trust in environmental groups, and trust in elected officials increase, while a respondent's likelihood of perceiving nuclear energy to be hazardous to human health decreases as age, individualism, hierarchism, trust in regulators, trust in regulations, objective knowledge, and subjective knowledge increase. We find that the first model already has moderate predictive accuracy (pseudo- $\mathrm{R}^{2}=.456$ ), but note that the model's explanatory power is increased once we add emotions (Model B pseudo- $\mathrm{R}^{2}$ $=.560)$. Notably, we find that all three emotions variables are significant correlates of health risk perception: as fright and anger increase, an individual's likelihood of perceiving health risks increases, and as excitement increases an individual's likelihood of perceiving such risks decreases. Further, we find that while objective knowledge, subjective knowledge and age remain significant variables in the second model, only one trust measure (elected officials) and none of the worldviews are significant.

To test whether the effect of emotions on risk perception varies between supporters and opponents of nuclear energy, we consider the full model (that is, the model including emotions, 
worldviews, trust, knowledge, and sociodemographic variables) across two split samples (see Table 3). The opponents sample $(\mathrm{N}=382)$ includes all respondents who responded "strongly oppose" or "somewhat oppose," and the "supporters" sample $(\mathrm{N}=897)$ includes all respondents who responded "strongly support" or "somewhat support" to the question, "When thinking of Saskatchewan's future involvement in the nuclear sector, would you strongly oppose, somewhat oppose, somewhat support or strongly support generating power from nuclear sources?" -- insert Table 3 about here--

Our split sample results suggest that emotions may have greater importance for supporters than opponents. We find that for the opponents, emotions are not significant correlates of risk-benefit perception, while one emotion - fright - is a significant correlate of both environmental and health risk perception: in each case, as fright increases, a respondent's likelihood of stating that nuclear energy presents risks increases. For the supporters, on the other hand, we find that excitement is a significant correlate of all three forms of risk perception, with risk perceptions decreasing as excitement increases; fright is related to both environmental and health risk perception, with risk perceptions increasing as fright increases; and anger is related to health risk perception, with risk perceptions increasing as anger increases. The split sample results also suggest that knowledge (a cognitive factor) may have a more consistent relationship with risk perception amongst opponents than supporters. Specifically, we find that objective knowledge is a significant correlate of all three risk perception measures amongst opponents, but is a significant correlate (along with subjective knowledge) of only health risk perception amongst supporters. 


\section{Discussion and Conclusion}

The purpose of this paper is to expand understanding of the effect of emotions on risk perceptions regarding contentious public issues to inform better public management of those issues. As previous research has focused primarily on negative emotions, our paper explores whether positive emotion, in the form of excitement, might also be relevant to risk perception. Further, contrary to the common portrayal of opponents (but not supporters) of contentious issues being driven by emotions, our paper explores whether the idea that supporters are more rational and non-emotional and opponents are more irrational and emotional might require further elaboration.

Our findings support previous research that connects emotion with risk perception. The results show that emotions are consistent correlates of risk/benefit, environmental risk, and health risk perception of nuclear power generation; indeed, in each case the inclusion of emotions increased the predictive accuracy of the model by roughly 10 percentage points. Further, once emotions were added to the model, other variables ceased to be statistically significant. We found that worldviews were significant correlates in the first block of each model, yet once emotions were added, the importance of worldviews diminished considerably. The trust measures were also affected by emotions variables in the model, suggesting that, when emotions are included, trust has a more limited relationship with risk perception than previously thought. This provides preliminary evidence that emotional experiences are so strong that cognitive factors (in the form of trust) and ideological factors (in the form of worldviews) may take a backseat when included in the same regression block. However, not all cognitive factors are influenced in the presence of emotions; the results suggest that emotions do not reduce the effects of knowledge on risk perception. 
We hypothesized that emotions are robust correlates of risk perception: that respondents who report negative emotions (anger and fear) will be more likely to perceive nuclear energy as risky, and that those who report positive emotions (excitement) will be less likely to perceive nuclear energy as risky. Our analysis finds support for these hypotheses. The data suggest that feeling frightened is a strong correlate of viewing nuclear power as dirty and hazardous, and feeling angry is a significant correlate of health risk and risk/benefit perception. Our findings suggest that not only negative but also positive emotions impact on risk perception: as respondents reported greater excitement about nuclear power, they were less likely to perceive risks as outweighing benefits, and less likely to believe nuclear power is environmentally dirty or hazardous to human health. The latter finding is interesting considering the measure of positive emotions - excitement - is arguably a more conservative test of this relationship because it is more extremely positive when compared to measures previously used in risk perception studies, such as interest, satisfaction, and optimism. In other words, one might expect fewer people to say they felt great levels of excitement than great levels of interest.

Because these findings about the importance of both positive and negative emotions are emergent, future research should further investigate this phenomenon and explanations for its occurrence. Given that the survey contains only one positive and two negative measures of emotion, it is beyond the scope of this study to draw conclusions about the broad range of emotions one might feel when thinking about nuclear activities or other contentious issues, such as contempt, sorrow, guilt, shame, worry, pessimism, interest, satisfaction, and optimism. Given the initial findings, further study of a range of both positive and negative feelings is warranted. Further, as cross-sectional data do not allow consideration of causal direction, it is plausible that risk perceptions influence emotions, rather than emotions influencing risk 
perceptions. Future research employing experimental design would help identify the causal relationship.

Our second research question was whether emotions have differing effects on risk perceptions of supporters and opponents of nuclear energy. We hypothesized that emotions are related to negative risk perception amongst opponents as well as positive risk perception amongst supporters. Only one of the two hypotheses received clear support. We found that emotions matter for all three measured forms of risk perception for supporters of nuclear energy: as excitement increases, supporters are less likely to feel risks outweigh benefits, that nuclear energy is environmentally dirty, or that it is hazardous to health; as fright increases, supporters are more likely to feel that there are environmental and health risks; and as anger increases, supporters are more likely to feel that nuclear energy is hazardous to health. In contrast, only one emotion - fright - is related to the risk perception of opponents: as fright increases, opponents are more likely to feel that there are environmental and health risks associated with nuclear energy. Excitement and anger are not related to opponents' risk perception, and emotions are not associated with opponents’ risk/benefit assessments.

These findings are a departure from historical perspectives on the role of emotion within the context of risk perception, where opponents have been characterized as emotional and supporters as rational. In contrast to these previous perspectives, we find that emotions play a role in the risk perception of both opponents and supporters. In fact, our findings suggest that emotions may play an even greater role amongst supporters as compared to opponents, a tentative observation requiring future research. Overall, this finding suggests that assumptions about the dominance of emotional factors as a key influence amongst opponents and about the dominance of knowledge as a key influence amongst supporters should be examined in future 
research. Our finding that excitement was a consistent correlate suggests researchers should consider that a person's feelings or experience of risk may include both negative and positive emotions.

These findings also speak to the relative role of cognition within the domain of risk perception. If, historically, opponents have been characterized as emotional and supporters as rational, one might have expected to see a more prominent role for the rational/cognitive factors in the models amongst supporters. This was not the case. In fact, cognitive factors appear to have taken a backseat to emotional factors. Again, these findings support the hypothesis that, drawing from theories of attitude formation, appraisals, and persuasion, human assessments across a range of views involve not only cognitive but also emotional factors.

Our findings contribute to public sector management and public administration by deepening our understanding of the behavioural nature of support and opposition to controversial policy issues. This understanding is especially important in the context of public participation in policy discussions, which include both opponents and supporters. A more profound recognition of these stakeholders allows organizers of participatory dialogues to do so more effectively.

The confirmation that emotions are consistent correlates of nuclear energy risk perception may have relevance for communications. A vast research finds that framing effects strongly influence individual attitudes. Given the influential role of emotions, it is possible that frames evoking particular emotional responses may be particularly effective in altering risk perception. Thus, while Costa-Font et al. $(2008,1276)$ argue, “Altering risk perceptions about nuclear technology remains difficult as perceptions appear to be divorced from technical risk assessments and more aligned to political beliefs or world views or feelings of dread," this analysis raises the question of whether appeals to particular emotions might be key to altering 
risk perception. Future research on framing effects should consider how emotions influence the effectiveness of different frames.

Throughout the discussion we have touched on this study's limitations; one final limitation is noteworthy. The context for this research was the province of Saskatchewan in Canada, a location that does not generate nuclear energy. People who are directly affected by the possibility of a nuclear accident are likely to demonstrate different emotions and risk perception as compared to those who do not live in the vicinity of nuclear power plants. While this might prevent the results from being replicable in contexts that have nuclear power, the comparison of positive and negative emotions across a range of support versus opposition within this context still generates meaningful conclusions. Furthermore, these results are insightful as society considers a range of contentious public sector issues, including but not limited to alternative energy sources.

Understanding risk perception is critical as contemporary societies struggle to make decisions where trade-offs between potential risks and benefits may be uncertain and, in particular, where the issue is contentious and complex. Our research acknowledges that risk perception is not only informed by what people know, how they think, and who they trust, but is also profoundly related to feelings, both positive and negative. The relationship between emotion and risk perception is prominent across a range of opposition and support for nuclear power. Overall, this research is a reminder that to truly understand risk perception, one must consider both cognitive and affective factors. 


\section{REFERENCES}

Bak, H.J. (2001), "Education and Public Attitudes Toward Science: Implications for the "Deficit Model" of Education and Support for Science and Technology", Social Science Quarterly, Vol. 82 No. 4, pp. 779-795.

Besley, J.C. and Oh, S.H. (2014), “The Impact of Accident Attention, Ideology, and Environmentalism on American Attitudes Toward Nuclear Energy”, Risk Analysis, Vol. 34 No. 5, pp. 949-964.

Biel, A. and Dahlstrand, U. (1995), "Risk Perception and the Location for a Repository of Spent Nuclear Fuel”, Scandinavian Journal of Psychology, Vol. 36 No. 1, pp. 25-36.

Bord, R.J. and O'Connor, R.E. (1992), "Determinants of Risk Perceptions of a Hazardous Waste Site”, Risk Analysis, Vol. 12 No. 3, pp. 411-416.

Brossard, D. and Nisbet, M.C. (2007), “Deference to Scientific Authority Among a Low Information Public: Understanding U.S. Opinion on Agricultural Biotechnology”, International Journal of Public Opinion Research, Vol. 19 No. 1, pp. 24-52.

Cobb, M. and Macoubrie, J. (2004), "Public Perceptions about Nanotechnology: Risks, Benefits and Trust", Journal of Nanoparticle Research, Vol. 6 No. 4, pp. 395-405.

Costa-Font, J., Rudisill, C., and Mossialos, E. (2008), “Attitudes as an Expression of Knowledge and 'Political Anchoring': The Case of Nuclear Power in the United Kingdom”, Risk Analysis, Vol. 28 No. 5, pp. 1273-1288.

Dake, K. (1991), “Orienting Dispositions in the Perception of Risk: An Analysis of Contemporary Worldviews and Cultural Biases”, Journal of Cross-Cultural Psychology, No. 22, pp. 61-82. 
Dohle, S., Keller, C., and Siegrist, M. (2012), "Fear and Anger: Antecedents and Consequences of Emotional Responses to Mobile Communication", Journal of Risk Research, Vol. 15 No. 4, pp. 435-446.

Eagly, A. and Chaiken, S. (2007), “The Advantages of an Inclusive Definition of Attitude”, Social Cognition, Vol. 25 No. 5, pp. 582-602.

Earle, T.C. and Cvetkovich, G.T. (1995), Social Trust: Toward a Cosmopolitan Society. Westport, CT, Praeger Publishers.

Einwohner, R.L. (1999), “Gender, Class, and Social Movement Outcomes: Identity and Effectiveness in Two Animal Rights Campaigns", Gender \& Society, Vol. 13 No. 1, pp. $56-79$.

European Commission. 2010. "Europeans and Nuclear Safety Report” Special EUROBAROMETER 324. Accessed January 2, 2015. http://ec.europa.eu/energy/nuclear/safety/doc/2010_eurobarometer_safety.pdf.

Fahlquist, J.N. and Roeser, S. (2015), “Nuclear Energy, Responsible Risk Communication and Moral Emotions: A Three Level Framework”, Journal of Risk Research, Vol. 18 No. 3, pp. 333-346.

Finucane, M.L., Alhakami, A., Slovic, P., and Johnson, S.M. (2000), "The Affect Heuristic in Judgments of Risks and Benefits”, Journal of Behavioral Decision Making, Vol. 13 No. 1, pp. $1-17$.

Fischer, F. (1995), Evaluating Public Policy, Nelson Hall Publishers, Chicago, 175-203.

Fischer, F. (2003), Reframing Public Policy: Discursive Politics and Deliberative Practices, Oxford University Press, 205-220. 
Fischoff, B., Slovic, P., Lichtenstein, S., Read, S., and Combs, B. (1978), "How Safe is Safe Enough? A Psychometric Study of Attitudes Towards Technological Risks and Benefits", Policy Sciences, Vol. 9, pp. 127-152.

Flynn, J., Burns, W., Mertz, C.K., and Slovic, P. (1992), “Trust as a Determinant of Opposition to a High-Level Radioactive Waste Repository: Analysis of a Structural Model”, Risk Analysis, Vol. 12 No. 3, pp. 417-429.

Gaarder, E. (2011), “Where the Boys Aren't: The Predominance of Women in Animal Rights Activism", Feminist Formulations, Vol. 23 No. 2, pp. 54-76.

Greenberg, M, and Truelove, H. (2010), "Right Answers and Right-Wrong Answers: Sources of Information Influencing Knowledge of Nuclear-Related Information”, Socio-Economic Planning Sciences, Vol. 44 No. 3, pp. 130-140.

Halachmi, A. (2005), “Governance and Risk Management: Challenges and Public Productivity”, International Journal of Public Sector Management, Vol. 18 No. 4, 300-317.

Hallman, W.K., and Wandersman, A.H. (1995), "Present Risk, Future Risk or No Risk? Measuring and Predicting Perceptions of Health Risks of a Hazardous Waste Landfill”, Risk: Health, Safety \& Environment, Vol. 6 (Summer), pp. 261-280.

Hirsch, R.A. and Baxter, J. (2011), “Context, Cultural Bias, and Health Risk Perception: The 'Everyday’ Nature of Pesticide Policy Preferences in London, Calgary, and Halifax”, Risk Analysis, Vol. 31 No. 5, pp. 847-865.

Hood, J. and Smith, T. (2013), "Perceptions of Quantifiable Benefits of Local Authority Risk Management," International Journal of Public Sector Management, Vol. 26 No. 4, 309319. 
Izard, C.E. (2010), “The Many Meanings/Aspects of Emotion: Definitions, Functions, Activation, and Regulation", Emotion Review, No. 2, pp. 363-370.

Jones, B.D. (2003), "Bounded Rationality and Political Science: Lessons from Public Administration and Public Policy," Journal of Public Administration Research and Theory, Vol. 13 No. 4, pp. 395-412.

Keller, C., Bostrom, A., Kuttschreuter, M., Savadori, L., Spence, A., and White, M. (2012), "Bringing Appraisal Theory to Environmental Risk Perception: A Review of Conceptual Approaches of the Past 40 Years and Suggestions for Future Research”, Journal of Risk Research, Vol. 15 No. 3, pp. 237-256.

King, C.S., Feltey, K.M., and O’Neill Susel, B. (1998), “The Question of Participation: Toward Authentic Public Participation in Public Administration”, Public Administration Review, Vol. 58 No. 4, pp. 317-326.

Lazarus, R.S. (1991), Emotion and Adaptation, Oxford University Press, New York.

Lee, C.J., Scheufele, D.A., and Lewenstein, B.V. (2005), "Public Attitudes Toward Emerging Technologies Examining the Interactive Effects of Cognitions and Affect on Public Attitudes Toward Nanotechnology”, Science Communication, Vol. 27 No. 2, pp. 240 267.

Lerner, J.S. and Keltner, D. (2001), “Fear, Anger, and Risk”, Journal of Personality and Social Psychology, Vol. 81 No. 1, pp. 146-159.

Loewenstein, G.F., Weber, E.U., Hsee, C.K., and Welch, E.S. (2001), "Risk as Feelings", Psychological Bulletin, Vol. 127 No. 2, pp. 267-286.

Maharik, M., and Fischhoff, B. (1993), "Risk Knowledge and Risk Attitudes Regarding Nuclear Energy Sources in Space”, Risk Analysis, Vol. 13 No. 3, pp. 345-353. 
Marris, A.C., Langford, I.H., and O'Riordan, T. (1998), “A Quantitative Test of the Cultural Theory of Risk Perceptions: Comparison with the Psychometric Paradigm", Risk Analysis, Vol. 18 No. 5, pp. 635-647.

Mcbeth, M.K. and Oakes, A.S. (1996), “Citizen Perceptions of Risks Associated with Moving Radiological Waste", Risk Analysis, Vol. 16 No. 3, pp. 421-427.

Oltedal, S., Moen, B.E., Klempe, H., and Rundmo, T. (2004), “Explaining Risk Perception: An Evaluation of Cultural Theory", Norwegian University of Science and Technology, No. 85, pp. 1-33.

Peters, E. and Slovic, P. (1996), "The Role of Affect and Worldviews as Orienting Dispositions in the Perception and Acceptance of Nuclear Power", Journal of Applied Social Psychology, Vol. 26 No. 16, pp. 1427-1453.

Peters, E.M., Burraston, B., and Mertz, C.K. (2004), “An Emotion-Based Model of Risk Perception and Stigma Susceptibility: Cognitive Appraisals of Emotion, Affective Reactivity, Worldviews, and Risk Perceptions in the Generation of Technological Stigma", Risk Analysis, Vol. 24 No. 5, pp. 1349-1367.

Petty, R.E. and Cacioppo, J.T. (1986), “The Elaboration Likelihood Model of Persuasion”, Advances in Experimental Social Psychology, Vol. 19, pp. 123-205.

Pijawka, K.D. and Mushkatel, A.H. (1992) "Public Opposition to the Siting of the High-Level Nuclear Waste Repository: The Importance of Trust”, Policy Studies Review, No.10, pp. $180-194$.

Savadori, L., Savio, S., Nicotra, E., Rumiati, R., Finucane, M.L., and Slovic, P. (2004), “Expert and Public Perception of Risk from Biotechnology", Risk Analysis, Vol. 24 No. 5, pp. $1289-1299$. 
Schwarz, N. (2011), "Feelings-as-Information Theory", in Vol 1 of Handbook of Theories of Social Psychology, edited by Van Lange, P.A.M., Kruglanski, A.W., and Higgins, E.T., Sage Publications, Thousand Oaks, pp. 289-308.

Schwarz, N. and Clore, G.L. (1996), “Feelings and Phenomenal Experiences”, In Vol. 2 of Social Psychology: Handbook of Basic Principles, edited by Kruglanski, A.W. and Higgins, E.T., Guilford Press, New York, pp. 385-407.

Siegrist, M. and Cvetkovich, G. (2000), "Perceptions of Hazards: The Role of Social Trust and Knowledge", Risk Analysis, Vol. 20 No. 5, pp. 713-720.

Siegrist, M., Gutscher, H., and Earle, T.C. (2005), "Perception of Risk: The Influence of General Trust, and General Confidence”, Journal of Risk Research, Vol. 8 No. 2, pp. 145-156.

Sjöberg, L. (1998a), "Worry and Risk Perception”, Risk Analysis, Vol. 18 No. 1, pp. 85-93.

Sjöberg, L. (1998b), "World Views, Political Attitudes and Risk Perception”, Risk: Health, Safety, and Environment, Vol. 9 (Spring), pp. 137-152.

Sjöberg, L. (1999a), "Risk Perception by the Public and by Experts: A Dilemma in Risk Management", Human Ecology Review, Vol. 6 No. 2, pp. $1-9$.

Sjöberg, L. (1999b), "Perceived Competence and Motivation in Industry and Government as Factors in Risk Perception Social in Trust and the Management of Risk", in Cvetkovich, G. and Lofstedt, R. E. (Eds.), Social Trust and the Management of Risk, Earthscan by Routledge, New York, pp. 89-99.

Sjöberg, L. (2003), "Risk Perception, Emotion and Policy: The Case of Nuclear Technology”, European Review, Vol. 11 No. 1, pp. 109-128.

Sjöberg, L. (2006), “Rational Risk Perception: Utopia or Dystopia?”, Journal of Risk Research, Vol. 9 No. 6, pp. 683-696. 
Sjöberg, L. (2007), “Emotions and Risk Perception”, Risk Management, Vol. 9 No. 4, pp. 223237.

Sjöberg, L. and Drottz-Sjöberg, B.M. (1991), "Knowledge and Risk Perception Among Nuclear Power Plant Employees", Risk Analysis, Vol. 11 No. 4, pp. 607-618.

Sjöberg, L., Moen, B.E., and Rundmo, T. (2004), Explaining Risk Perception. An Evaluation of the Psychometric Paradigm in Risk Perception Research, Rotunde, Trondheim.

Slovic, P. (1987), "Perception of Risk”, Science, 236, pp. 280-285.

Slovic, P. (1999), “Trust, Emotion, Sex, Politics, and Science: Surveying the Risk Assessment Battlefield”, Risk Analysis, Vol. 19 No. 4, pp. 689-701.

Slovic, P., Peters, E., Finucane, M.L., and MacGregor, D.G. (2005), “Affect, Risk, and Decision Making”, Health Psychology, Vol. 24 No. 4S, pp. S35-S40.

Slovic, P., Flynn, J.H., and Layman, M. (1991), "Perceived Risk, Trust, and the Politics of Nuclear Waste”, Science, Vol. 254 No. 5038, pp. 1603-1607.

Sparks, P., Shepherd, R., and Frewer, L.J. (1994), “Gene Technology, Food Production, and Public Opinion: A UK Study", Agriculture and Human Values, Vol. 11 No. 1, pp. 19-28. Uranium Development Partnership. 2009. Capturing the Full Potential of the Uranium Value Chain in Saskatchewan. Report prepared for the Government of Saskatchewan Ministry of Energy and Resources. Accessed December 20, 2013. http://www.gov.sk.ca/adx/aspx/adxGetMedia.aspx?mediaId=767\&PN=Shared.

World Nuclear Association, (2013), "Nuclear power in Canada", available at: http://www.world-nuclear.org/info/Country-Profiles/Countries-A-F/Canada. (accessed January 19, 2014). 


\section{TABLE 1: MEASURES}

\begin{tabular}{|c|c|}
\hline Measures & Item Wording and Coding \\
\hline Risk-benefit & $\begin{array}{l}\text { Which of the following best reflects your opinion: the benefits of nuclear power generation far outweigh the risks; the benefits of nuclear } \\
\text { power generation slightly outweigh the risks; the benefits and risks of nuclear power generation are about the same; the risks of nuclear power } \\
\text { generation slightly outweigh the benefits; the risks of nuclear power generation far outweigh the benefits? (risks outweigh benefits = } 1 \text {, } \\
\text { benefits equal or outweigh risks }=0 \text { ) }\end{array}$ \\
\hline $\begin{array}{l}\text { Environmental } \\
\text { risk }\end{array}$ & $\begin{array}{l}\text { To the best of your knowledge, is nuclear power generation an environmentally dirty or an environmentally clean option for electricity } \\
\text { production? (dirty }=1 \text {, clean }=0 \text { ) }\end{array}$ \\
\hline Health risk & $\begin{array}{l}\text { To the best of your knowledge, is nuclear power generation hazardous to human health or is it safe for human health? }(\text { hazardous }=1 \text {, safe }= \\
0)\end{array}$ \\
\hline Excitement & I am excited by the idea of nuclear power generation in Saskatchewan. (strongly disagree $=1$, strongly agree $=4$ ) \\
\hline Fear & I am frightened by the idea of nuclear power generation in Saskatchewan. (strongly disagree $=1$, strongly agree $=4$ ) \\
\hline Anger & I am angered by the idea of nuclear power generation in Saskatchewan. (strongly disagree $=1$, strongly agree $=4$ ) \\
\hline $\begin{array}{l}\text { Objective } \\
\text { knowledge }\end{array}$ & $\begin{array}{l}\text { Count variable of correct responses to four questions. } \\
\text { As far as you know, ... } \\
\ldots \text { is radiation only a man-made phenomenon that comes from sources such as power facilities and x-ray machines? }(\text { Correct }=\text { no }) \\
\ldots \text { which mineral resource is mined in Saskatchewan that is fundamentally important for nuclear power generation? }(\text { Correct }=\text { uranium }) \\
\ldots \text { does Saskatchewan currently use nuclear power to generate electricity? }(\text { Correct }=\text { no }) \\
\ldots \text { does Saskatchewan currently store nuclear fuel waste? }(\text { Correct }=\text { no })\end{array}$ \\
\hline $\begin{array}{l}\text { Subjective } \\
\text { knowledge }\end{array}$ & $\begin{array}{l}\text { Overall, how would you rate your personal knowledge about nuclear topics? Would you say that it is: very good, good, moderate, poor, very } \\
\text { poor? (very poor }=1 \text {, very good }=5 \text { ) }\end{array}$ \\
\hline Worldviews & $\begin{array}{l}\text { Means-based scales (strongly disagree=1, strongly agree=4). } \\
\text { Hierarchical }(\alpha=0.540) \text { : Decisions about health risks should be left to the experts; Until public health officials alert me about a specific } \\
\text { serious health problem, I don't really have to worry; With expert management, we can prevent major environmental problems. } \\
\text { Individualist ( } \alpha=0.539) \text { : A strong economy can only exist by giving companies the opportunity to prosper; Continued economic growth is } \\
\text { necessary to improve our quality of life; The environment is very adaptable and will recover from any harm caused by people. } \\
\text { Egalitarian }(\alpha=0.503) \text { : Misuse of scientific and expert knowledge is a very serious problem in society today; Those in power often withhold } \\
\text { information about things that are harmful to us; The environment is very fragile and the slightest human interference can cause major } \\
\text { problems. }\end{array}$ \\
\hline Trust & $\begin{array}{l}\text { Series of individual questions, order randomized with the exception of regulations (asked last). } \\
\text { On a scale of } 1 \text { to } 5 \text {, where } 1 \text { means you 'do not trust them at all' and } 5 \text { means you 'trust them completely', how much do you trust ... } \\
\text { University scientists? Government nuclear regulators? Industry representatives? Elected officials? Environmental groups? The adequacy of } \\
\text { Canada's nuclear regulations? }\end{array}$ \\
\hline
\end{tabular}


TABLE 2: EMOTIONS AND RISK PERCEPTION (LOGIT), FULL SAMPLE

\begin{tabular}{|c|c|c|c|c|c|c|c|c|c|c|c|c|c|c|c|c|c|c|}
\hline & \multicolumn{6}{|c|}{ Risks greater than benefits } & \multicolumn{6}{|c|}{ Environmentally dirty } & \multicolumn{6}{|c|}{ Hazardous to health } \\
\hline & \multicolumn{3}{|c|}{ Model A } & \multicolumn{3}{|c|}{ Model B } & \multicolumn{3}{|c|}{ Model A } & \multicolumn{3}{|c|}{ Model B } & \multicolumn{3}{|c|}{ Model A } & \multicolumn{3}{|c|}{ Model B } \\
\hline & $\mathrm{B}$ & SE & $\operatorname{Exp}(\mathrm{B})$ & $\mathrm{B}$ & SE & Exp (B) & $\mathrm{B}$ & SE & Exp (B) & $\mathrm{B}$ & SE & $\operatorname{Exp}(\mathrm{B})$ & $\mathrm{B}$ & SE & $\operatorname{Exp}(\mathrm{B})$ & $\mathrm{B}$ & $\mathrm{SE}$ & $\operatorname{Exp}(\mathrm{B})$ \\
\hline Male & -.142 & .195 & .868 & .037 & .211 & 1.038 & -.195 & .205 & .823 & .057 & .221 & 1.059 & -.169 & .202 & .845 & .114 & .222 & 1.121 \\
\hline Age & $-.012 \mathrm{c}$ & .006 & .988 & $-.014 \mathrm{c}$ & .006 & .986 & $-.036 \mathrm{a}$ & .006 & 965 & $-.042 \mathrm{a}$ & .007 & .959 & $-.020 \mathrm{~b}$ & .006 & .980 & $-.025 \mathrm{a}$ & .007 & .975 \\
\hline Education & -.035 & .050 & .965 & -.010 & .054 & .990 & .044 & .053 & 1.045 & .087 & .058 & 1.091 & -.027 & .052 & .973 & .029 & .057 & 1.029 \\
\hline Income & -.046 & .048 & .955 & -.048 & .052 & .953 & $-.105 \mathrm{c}$ & .049 & .900 & $-.114 \mathrm{c}$ & .053 & .892 & -.065 & .049 & .937 & -.060 & .054 & .942 \\
\hline \multicolumn{19}{|l|}{ WORLDVIEWS } \\
\hline Hierarchical & -.293 & .156 & .746 & -.111 & .169 & .895 & $-.410 \mathrm{c}$ & .166 & .664 & -.181 & .181 & .835 & $-.464 c$ & .166 & .629 & -.172 & .184 & .842 \\
\hline Individualist & -.283 & .158 & .753 & .087 & .178 & 1.091 & -.227 & .169 & .797 & .190 & .191 & 1.209 & $-.537 b$ & .171 & .584 & -.143 & .194 & .867 \\
\hline Egalitarian & $.829 \mathrm{a}$ & .187 & 2.291 & $.551 \mathrm{c}$ & .199 & 1.734 & $.553 \mathrm{c}$ & .191 & 1.739 & .224 & .208 & 1.251 & $.729 a$ & .178 & 2.074 & .380 & .197 & 1.462 \\
\hline \multicolumn{19}{|l|}{ TRUST } \\
\hline Scientists & $-.303 c$ & .111 & .739 & -.165 & .120 & .847 & -.171 & .119 & .843 & -.070 & .131 & .933 & -.142 & .124 & .868 & -.021 & .135 & .980 \\
\hline Regulators & -.202 & .111 & .817 & -.104 & .119 & .901 & $-.251 \mathrm{c}$ & .117 & .778 & -.145 & .126 & .865 & $-.340 b$ & .116 & .712 & -.250 & .130 & .779 \\
\hline Industry & -.125 & .115 & .883 & .010 & .122 & 1.010 & $-.258 \mathrm{c}$ & .119 & .772 & -.191 & .126 & .826 & -.121 & .117 & .886 & .057 & .128 & 1.059 \\
\hline Elected officials & .060 & .107 & 1.061 & .009 & .114 & 1.009 & $.300 \mathrm{c}$ & .114 & 1.349 & $.293 \mathrm{c}$ & .122 & 1.340 & $.378 b$ & .114 & 1.459 & $.361 \mathrm{~b}$ & .125 & 1.435 \\
\hline Environmental & $.270 \mathrm{~b}$ & .092 & 1.310 & .091 & .101 & 1.095 & $.385 \mathrm{a}$ & .096 & 1.470 & $.214 \mathrm{c}$ & .106 & 1.239 & $.346 a$ & .094 & 1.414 & .113 & .105 & 1.120 \\
\hline Regulations & -.144 & .112 & .866 & -.039 & .121 & .962 & -.223 & .121 & .800 & -.158 & .130 & .854 & $-.290 \mathrm{c}$ & .119 & .748 & -.245 & .132 & .782 \\
\hline \multicolumn{19}{|l|}{ KNOWLEDGE } \\
\hline Objective & .130 & .087 & 1.139 & .101 & .092 & 1.107 & $-.291 \mathrm{~b}$ & .089 & .748 & $-.334 \mathrm{~b}$ & .096 & .716 & $-.429 \mathrm{a}$ & .090 & .651 & $-.480 \mathrm{a}$ & .099 & .619 \\
\hline Subjective & .064 & .102 & 1.066 & .080 & .111 & 1.083 & .076 & .108 & 1.079 & .153 & .117 & 1.165 & $-.298 \mathrm{c}$ & .106 & .742 & $-.268 \mathrm{c}$ & .116 & .765 \\
\hline \multicolumn{19}{|l|}{ EMOTIONS } \\
\hline Frightened & & & & .156 & .120 & 1.169 & & & & $.591 \mathrm{a}$ & .129 & 1.806 & & & & $.546 a$ & .130 & 1.727 \\
\hline Angry & & & & $.289 \mathrm{c}$ & .125 & 1.335 & & & & .004 & .137 & 1.004 & & & & $.433 b$ & .139 & 1.542 \\
\hline Excited & & & & $-.745 a$ & .130 & .475 & & & & $-.643 a$ & .142 & .526 & & & & $-.495 \mathrm{a}$ & .137 & .610 \\
\hline Constant & .069 & 1.145 & 1.072 & -.653 & 1.329 & .520 & $2.530 \mathrm{c}$ & 1.223 & 12.554 & 1.215 & 1.378 & 3.370 & $4.867 \mathrm{a}$ & 1.154 & 129.912 & 2.458 & 1.339 & 11.686 \\
\hline Pseudo $\mathrm{R}^{2}$ & \multicolumn{3}{|c|}{.288} & \multicolumn{3}{|c|}{.397} & \multicolumn{3}{|c|}{.371} & \multicolumn{3}{|c|}{.473} & \multicolumn{3}{|c|}{.456} & \multicolumn{3}{|c|}{.560} \\
\hline Model Chi-Sq. & \multicolumn{3}{|c|}{$180.657 \mathrm{a}$} & \multicolumn{3}{|c|}{$260.685 \mathrm{a}$} & \multicolumn{3}{|c|}{$230.636 \mathrm{a}$} & \multicolumn{3}{|c|}{$308.727 \mathrm{a}$} & \multicolumn{3}{|c|}{$319.710 \mathrm{a}$} & \multicolumn{3}{|c|}{$415.501 \mathrm{a}$} \\
\hline $\mathrm{N}$ & & & & & & & & & & & & & & & & & & \\
\hline
\end{tabular}

Note: Data are weighted. a: $\mathrm{p}<.001, \mathrm{~b}: \mathrm{p}<.01$ and $\mathrm{c}: \mathrm{p}<.05$. Pseudo $\mathrm{R}^{2}$ used is Nagelkerke 
TABLE 3: EMOTIONS AND RISK PERCEPTION (LOGIT), SPLIT SAMPLES

\begin{tabular}{|c|c|c|c|c|c|c|c|c|c|c|c|c|c|c|c|c|c|c|}
\hline & \multicolumn{6}{|c|}{ Risks greater than benefits } & \multicolumn{6}{|c|}{ Environmentally dirty } & \multicolumn{6}{|c|}{ Hazardous to health } \\
\hline & \multicolumn{3}{|c|}{ Opponents } & \multicolumn{3}{|c|}{ Supporters } & \multicolumn{3}{|c|}{ Opponents } & \multicolumn{3}{|c|}{ Supporters } & \multicolumn{3}{|c|}{ Opponents } & \multicolumn{3}{|c|}{ Supporters } \\
\hline & B & SE & Exp (B) & B & SE & $\operatorname{Exp}(B)$ & B & $\mathrm{SE}$ & $\begin{array}{l}\text { Exp } \\
\text { (B) }\end{array}$ & B & $\mathrm{SE}$ & Exp (B) & B & SE & Exp (B) & $\mathrm{B}$ & SE & $\operatorname{Exp}(B)$ \\
\hline Male & -.199 & .372 & .820 & -.111 & .302 & .895 & .476 & .387 & 1.610 & -.379 & .319 & .685 & .134 & .525 & 1.144 & .154 & .265 & 1.166 \\
\hline Age & .009 & .012 & 1.009 & $-.017 \mathrm{c}$ & .008 & .983 & $-.037 \mathrm{c}$ & .013 & .963 & $-.044 \mathrm{a}$ & .010 & .957 & -.009 & .019 & .991 & $-.027 \mathrm{a}$ & .008 & .973 \\
\hline Education & .102 & .098 & 1.107 & -.075 & .079 & .928 & .156 & .104 & 1.168 & .049 & .086 & 1.050 & .158 & .149 & 1.172 & .011 & .066 & 1.011 \\
\hline Income & -.037 & .100 & .963 & -.056 & .070 & .946 & -.011 & .106 & .989 & -.031 & .071 & .969 & -.221 & .133 & .802 & .010 & .062 & 1.010 \\
\hline \multicolumn{19}{|l|}{ WORLDVIEWS } \\
\hline Hierarchical & .159 & .285 & 1.173 & -.050 & .263 & .952 & -.173 & .298 & .841 & .119 & .283 & 1.126 & .171 & .426 & 1.187 & -.190 & .224 & .827 \\
\hline Individualist & .603 & .330 & 1.828 & -.074 & .248 & .929 & -.077 & .331 & .926 & $.734 \mathrm{c}$ & .295 & 2.083 & -.214 & .452 & .807 & .063 & .226 & 1.065 \\
\hline Egalitarian & $.988 \mathrm{c}$ & .383 & 2.687 & $.591 \mathrm{c}$ & .268 & 1.807 & .560 & .392 & 1.751 & -.141 & .282 & .869 & $1.234 \mathrm{c}$ & .525 & 3.436 & .276 & .226 & 1.318 \\
\hline \multicolumn{19}{|l|}{ TRUST } \\
\hline Scientists & -.297 & .206 & .743 & -.164 & .172 & .849 & -.369 & .222 & .691 & .258 & .214 & 1.294 & .010 & .315 & 1.010 & -.022 & .162 & .979 \\
\hline Regulators & -.029 & .194 & .971 & -.153 & .174 & .858 & -.279 & .195 & .757 & .018 & .193 & 1.018 & -.072 & .285 & .931 & -.274 & .156 & .761 \\
\hline Industry & .006 & .222 & 1.006 & .119 & .176 & 1.126 & .326 & .226 & 1.385 & $-.540 \mathrm{~b}$ & .179 & .583 & .497 & .323 & 1.645 & -.056 & .152 & .946 \\
\hline Elected officials & $-.542 \mathrm{c}$ & .205 & .582 & $.323 \mathrm{c}$ & .160 & 1.381 & .043 & .217 & 1.044 & $.365 \mathrm{c}$ & .178 & 1.441 & .475 & .330 & 1.608 & $.319 \mathrm{c}$ & .144 & 1.376 \\
\hline Environmental & .118 & .187 & 1.126 & .044 & .140 & 1.045 & .054 & .183 & 1.056 & $.485 b$ & .161 & 1.624 & .092 & .263 & 1.097 & .132 & .124 & 1.141 \\
\hline Regulations & -.140 & .219 & .869 & .097 & .175 & 1.102 & -.043 & .229 & .958 & $-.393 c$ & .193 & .675 & $-.768 c$ & .343 & .464 & -.179 & .152 & .836 \\
\hline \multicolumn{19}{|l|}{ KNOWLEDGE } \\
\hline Objective & $.435 \mathrm{c}$ & .170 & 1.545 & -.004 & .132 & .996 & $-.401 c$ & .185 & .670 & -.224 & .132 & .799 & $-.970 b$ & .331 & .379 & $-.381 b$ & .111 & .683 \\
\hline Subjective & -.135 & .189 & .874 & .065 & .165 & 1.067 & .183 & .202 & 1.201 & .245 & .185 & 1.278 & .095 & .268 & 1.100 & $-.350 \mathrm{c}$ & .142 & .705 \\
\hline \multicolumn{19}{|l|}{ EMOTIONS } \\
\hline Frightened & .386 & .212 & 1.471 & -.179 & .199 & .836 & $.662 b$ & .214 & 1.938 & $.676 b$ & .215 & 1.966 & $.573 \mathrm{c}$ & .284 & 1.774 & $.523 \mathrm{~b}$ & .170 & 1.687 \\
\hline Angry & -.068 & .221 & .934 & .216 & .207 & 1.241 & -.226 & .230 & .797 & -.312 & .249 & .732 & .180 & .290 & 1.198 & $.607 \mathrm{~b}$ & .187 & 1.836 \\
\hline Excited & -.423 & .264 & .655 & $-.734 a$ & .187 & .480 & -.115 & .296 & .891 & $-.679 b$ & .231 & .507 & .337 & .434 & 1.401 & $-.450 \mathrm{~b}$ & .172 & .637 \\
\hline Constant & -3.989 & 2.737 & .019 & -.325 & 1.81 & .722 & .743 & 2.80 & 2.102 & -1.529 & 1.91 & .217 & -2.076 & 4.08 & .125 & 1.905 & 1.55 & 6.720 \\
\hline Pseudo $\mathrm{R}^{2}$ & \multicolumn{3}{|c|}{.267} & \multicolumn{3}{|c|}{.153} & \multicolumn{3}{|c|}{.290} & \multicolumn{3}{|c|}{.338} & \multicolumn{3}{|c|}{.429} & \multicolumn{3}{|c|}{.424} \\
\hline Model Chi-Sq. & \multicolumn{3}{|c|}{$45.792 \mathrm{a}$} & \multicolumn{3}{|c|}{$48.254 a$} & \multicolumn{3}{|c|}{$46.145 \mathrm{a}$} & \multicolumn{3}{|c|}{$113.415 \mathrm{a}$} & \multicolumn{3}{|c|}{$59.351 \mathrm{a}$} & \multicolumn{3}{|c|}{$192.060 \mathrm{a}$} \\
\hline $\mathrm{N}$ & & 219 & & & 544 & & & 202 & & & 509 & & & 210 & & & 521 & \\
\hline
\end{tabular}

Note: Data are weighted. a: $\mathrm{p}<.001, \mathrm{~b}: \mathrm{p}<.01$ and $\mathrm{c}: \mathrm{p}<.05$. Pseudo $\mathrm{R}^{2}$ used is Nagelkerke. 